\title{
Zu den HerausgeberInnen
}

Anka Bergmann ist Professorin für Fachdidaktik Russisch an der HumboldtUniversität zu Berlin. Zu ihren Arbeitsgebieten zählen bildungspolitische Rahmenbedingungen des schulischen Fremdsprachenunterrichts, Heterogenität und Differenzierung im Russischunterricht, Lernersprachenanalyse, Mehrsprachigkeit und Sprachenlernen.

Olga Caspers ist Senior Lecturer am Institut für Slawistik der Humboldt-Universität zu Berlin. Ihre Arbeitsschwerpunkte sind Inter- und Transkulturalität, russische Literatur des 19.-21. Jh., Alltagskultur, Visual Studies und Medienanalyse.

Wolfgang Stadler ist Professor für Fachdidaktik Russisch und Russische Sprachwissenschaft an der Universität Innsbruck. Seine Forschungsinteressen liegen im Bereich der Fremdsprachendidaktik, der Pragmatik und Soziolinguistik sowie der Testforschung und der Leistungsbeurteilungskompetenz im schulischen und universitären Kontext. 